Article

\title{
Development and Validation of Two Self-Reported Tools for Insulin Resistance and Hypertension Risk Assessment in a European Cohort: The Feel4Diabetes-Study
}

\author{
Spyridon Kanellakis ${ }^{1}$, Christina Mavrogianni ${ }^{1}$, Kalliopi Karatzi ${ }^{1}$, Jaana Lindstrom ${ }^{2}$, \\ Greet Cardon ${ }^{3}\left(\mathbb{D}\right.$, Violeta Iotova ${ }^{4}(\mathbb{D})$, Katja Wikström ${ }^{2}$, Samyah Shadid ${ }^{5}$, Luis A. Moreno ${ }^{6,7,8,9}{ }^{(D)}$, \\ Kaloyan Tsochev ${ }^{4}$, Éva Bíró ${ }^{10}$ (D), Rumyana Dimova ${ }^{11}$, Emese Antal ${ }^{12}$, Stavros Liatis ${ }^{13}$, \\ Konstantinos Makrilakis ${ }^{13}$ (D), Yannis Manios ${ }^{1, *}$ and on behalf of the Feel4Diabetes-study group ${ }^{\dagger}$ \\ 1 Department of Nutrition and Dietetics, School of Health Science and Education, Harokopio University, \\ 17671 Athens, Greece; kanellakis@hua.gr (S.K.); cmavrog@hua.gr (C.M.); pkaratzi@hua.gr (K.K.) \\ 2 Department of Public Health Solutions, Finnish Institute for Health and Welfare, 00271 Helsinki, Finland; \\ jaana.lindstrom@thl.fi (J.L.); katja.wikstrom@thl.fi (K.W.) \\ 3 Department of Movement and Sports Sciences, Faculty of medicine and Health Sciences, Ghent University, \\ 9000 Gent, Belgium; Greet.Cardon@ugent.be \\ 4 Department of Paediatrics, Medical University Varna, 9002 Varna, Bulgaria; \\ violeta.iotova@mu-varna.bg (V.I.); kalooyan@abv.bg (K.T.) \\ 5 Department of Endocrinology, Ghent University Hospital, 9000 Gent, Belgium; samyah.shadid@uzgent.be \\ 6 Growth, Exercise, Nutrition and Development Research Group, School of Health Sciences, \\ University of Zaragoza, 50009 Zaragoza, Spain; Imoreno@unizar.es \\ 7 Instituto Agroalimentario de Aragón (IA2), 50009 Zaragoza, Spain \\ 8 Instituto de Investigación Sanitaria de Aragón (IIS Aragón), 50009 Zaragoza, Spain \\ 9 Centro de Investigación Biomédica en Red de Fisiopatología de la Obesidad y Nutrición (CIBERObn), \\ Instituto de Salud Carlos III, 28029 Madrid, Spain \\ 10 Division of Health Promotion, Department of Preventive Medicine, Faculty of Public Health, \\ University of Debrecen, 4032 Debrecen, Hungary; biro.eva@sph.unideb.hu \\ 11 Department of Diabetology, Clinical Center of Endocrinology, Medical University Sofia, 1431 Sofia, Bulgaria; \\ dr.roumyana.dimova@gmail.com \\ 12 Hungarian Society of Nutrition, 1088 Budapest, Hungary; diet.Emese.Antal@gmail.com \\ 13 National and Kapodistrian University of Athens Medical School, 11527 Athens, Greece; \\ s.liatis@yahoo.com (S.L.); kmakrila@med.uoa.gr (K.M.) \\ * Correspondence: manios@hua.gr; Tel.: +30-210-954-9156 \\ + Membership of the Feel4Diabetes-study group is provided in the Acknowledgments.
}

Received: 3 March 2020; Accepted: 26 March 2020; Published: 30 March 2020

check for updates

\begin{abstract}
Early identification of type 2 diabetes mellitus (T2DM) and hypertension (HTN) risk may improve prevention and promote public health. Implementation of self-reported scores for risk assessment provides an alternative cost-effective tool. The study aimed to develop and validate two easy-to-apply screening tools identifying high-risk individuals for insulin resistance (IR) and HTN in a European cohort. Sociodemographic, lifestyle, anthropometric and clinical data obtained from 1581 and 1350 adults (baseline data from the Feel4Diabetes-study) were used for the European IR and the European HTN risk assessment index respectively. Body mass index, waist circumference, sex, age, breakfast consumption, alcohol, legumes and sugary drinks intake, physical activity and sedentary behavior were significantly correlated with Homeostatic Model Assessment of IR (HOMA-IR) and/or HTN and incorporated in the two models. For the IR index, the Area Under the Curve (AUC), sensitivity and specificity for identifying individuals above the 75th and 95th of HOMA-IR percentiles were 0.768 (95\%CI: 0.721-0.815), 0.720 and 0.691 and 0.828 (95\%CI: 0.766-0.890), 0.696 and 0.778 respectively. For the HTN index, the AUC, sensitivity and specificity were 0.778
\end{abstract}


(95\%CI: 0.680-0.876), 0.667 and 0.797. The developed risk assessment tools are easy-to-apply, valid, and low-cost, identifying European adults at high risk for developing T2DM or having HTN.

Keywords: European IR Risk Index; European HTN Risk Index; screening; type 2 diabetes; hypertension

\section{Introduction}

Despite the vast scientific research and the numerous health initiatives indicating that Type 2 Diabetes Mellitus (T2DM) is preventable, its prevalence is constantly rising. At the moment, 483 million people suffer from diabetes around the world. Although Europe holds the second lowest prevalence of $6.3 \%$, it is expected to increase to $7.3 \%$ and $7.8 \%$ by 2030 and 2045 , respectively [1]. Similarly, hypertension (HTN), which is the strongest risk factor for all-cause mortality globally [2], keeps on rising and affects one in four adults [3].

The importance of early identification of both T2DM and HTN has been well-documented [4-7]. The diagnosis of T2DM includes the assessment of fasting plasma glucose (FPG), 2-h plasma glucose during an oral glucose tolerance test, or glycated hemoglobin (HbA1c) measurement [8]. Furthermore, according to the European Society of HTN, measurement of blood pressure in various conditions, such as at the office or at home, or daytime versus night-time, determines its classification from optimal blood pressure (BP) to grade 3 HTN [9]. However, since people with HTN have no symptoms, they do not monitor their BP. Consequently, as shown in a recent review, $5-10 \%$ of subjects with stage 2 HTN are undiagnosed or untreated [10]. Either because of the cost of blood tests, the practical arrangements of being measured or the lack of symptoms, both for insulin resistance (IR) and high BP, many people do not perform regular checks and, consequently, diagnosis is only made often after severe complications have developed over time [11]. Therefore, the application of low-cost and easy-to-apply methods for the early diagnosis of pre-diabetes and HTN could be a useful tool for public health [12].

There is a growing number of screening tools assessing glycaemic and BP status via the incorporation of various risk factors such as age, history of disease, sex, ethnicity, body mass index (BMI), medication, etc. [13-17]. Regarding the manifestation of T2DM, there are many risk scores and indices in the literature. However, most of them incorporate measures of blood glucose, which is not always feasible to be measured, especially in populations of low socioeconomic status. Additionally, none of them has been developed based on a multiethnic population. Moreover, most of them do not take into account dietary habits as predictors $[13,15,18,19]$. Nonetheless, there is no risk score identifying IR. Impaired insulin sensitivity represents early abnormalities in glycaemic control and constitutes a great predictive index for T2DM $[20,21]$. In addition, the impact of IR on the capacity metabolic roles of liver, adipose tissue and skeletal muscle is detrimental for human health [22]. As for HTN, there are some prediction models developed, but their application does not suit to all ethnicities and races [23], age groups [14], or incorporate, as well, BP measurements [16]. This is impractical for many people as they do not regularly measure their BP, or it is misleading, as the reported BP measurement does not represent an accurate estimation due to lack of proper assessment according to the guidelines (i.e., standard conditions and measurements during three different visits) [24].

The aim of the current study was to develop and validate two risk assessment indices for the identification of adults with IR (European IR Risk Index) and grade 2 and 3 HTN (European HTN Risk index) via demographic, anthropometric, dietary and lifestyle parameters in a large European cohort. 


\section{Materials and Methods}

\subsection{Study Background}

The current study was based on the baseline data retrieved from the EU-funded Feel4Diabetes-study, which intended to design, apply and evaluate an intervention program in schools and communities in order to prevent T2DM among families across Europe. The Feel4Diabetes-study was registered at clinicaltrials.gov as NCT02393872.

\subsection{Ethics Approval and Consent to Participate}

The Feel4Diabetes-study adhered to the Declaration of Helsinki and the conventions of the Council of Europe on human rights and biomedicine [25]. All participating countries obtained ethical clearance from the relevant ethical committees and local authorities. More specifically, in Belgium the study was approved by the Medical Ethics Committee of the Ghent University Hospital (ethical approval code: B670201524437); in Bulgaria, by the Ethics Committee of the Medical University of Varna (ethical approval code: 52/10-3-2016r) and the Municipalities of Sofia and Varna, as well as the Ministry of Education and Science local representatives; in Finland, by the hospital district of Southwest Finland ethical committee (ethical approval code: 174/1801/2015); in Greece, by the Bioethics Committee of Harokopio University (ethical approval code: 46/3-4-2015) and the Greek Ministry of Education; in Hungary, by the National Committee for Scientific Research in Medicine (ethical approval code: 20095/2016/EKU); and in Spain, by the Clinical Research Ethics Committee and the Department of Consumers' Health of the Government of Aragón (ethical approval code: CP03/2016). All participants gave their written informed consent prior to their enrolment in the study.

\subsection{Study Protocol and Recruitment}

A detailed description of the methodology of the Feel4Diabetes-study has been previously published [26]. Briefly, the recruitment of the population study was carried out via a multi-stage sampling procedure in selected provinces of six European countries (Hungary, Bulgaria, Finland, Belgium, Greece and Spain). In each country, primary schools located in the selected municipalities were used as the entry-point to the community and parents having children attending the first three grades were invited to complete the Finnish Diabetes Risk Score (FINDRISC) and a brief questionnaire on lifestyle habits (self-reported data). If at least one parent fulfilled the country- specific cut-off point for FINDRISC (for the majority of countries that was set as a FINDRISC score $\geq 9$ ), both parents (regardless their individual FINDRISC score) were invited to undergo a brief medical check-up. This procedure led to a cohort with a wide distribution of FINDRISC values among the participating parents, i.e., $25.9 \%, 37.3 \%$ and $36.8 \%$ of participants had a total FINDRISC score $<9$, 9-11 and $\geq 12$ respectively.

Exclusion criteria for the development of the two risk assessment indices were: previous diabetes diagnosis, not following the fasting protocol, current antihypertensive treatment and incomplete data. Therefore, from the initial 3153 parents, 1572 were excluded from the Homeostatic Model Assessment of IR (HOMA-IR) index and 1786 were excluded from the HTN index, and this resulted in 1581 (Bulgaria, $n=367$; Finland, $n=218$; Belgium, $n=214$; Greece, $n=476$; and Spain, $n=306$ ) and 1350 (Hungary, $n=19$; Bulgaria, $n=361$; Finland, $n=278$; Belgium, $n=173$; and Greece, $n=519$ ) subjects for each model, respectively. Insulin data were not analyzed in Hungary, thus the data obtained from this country was not included the IR risk index. Similarly, the data obtained from Spain was excluded from the HTN risk index, as alcohol intake was not recorded in this cohort. Blood pressure and blood indices (i.e., insulin and glucose) were measured by trained researchers using standardized procedures and calibrated equipment in every country as described elsewhere [26]. All variables used in the two developed tools were self-reported (including anthropometric measurements). 


\subsection{Measures}

Questionnaire data: All the relevant data, such as sociodemographics (i.e., sex, age, educational level, marital status, etc.), behavioral indices regarding dietary habits, physical activity and sedentary behaviors (i.e., portions of sugary drinks per week, number of meals and snacks during a day, minutes of daily vigorous physical activity, time spent in front of computers and television, etc.) were collected from participants [26].

Anthropometry: All study participants received paper measuring tapes and brief written instructions on how to measure their height, weight and waist circumference. BMI and waist circumference were classified based on the World Health Organization (WHO) criteria [27].

BP measurement: BP was measured on the right arm, in a sitting position using electronic sphygmomanometers (OMRON M6 or OMRON M6 AC, Omron Healthcare, Kyoto, Japan) after five minutes of rest, on three occasions, at one-minute intervals. Participants were classified according to the European guidelines [28] in the following categories: optimal (systolic BP $<120 \mathrm{mmHg}$ and/or diastolic $\mathrm{BP}<80 \mathrm{mmHg}$ ), normal (systolic BP 120-129 mmHg and/or diastolic BP 80-84 mmHg), high normal (systolic BP 130-139 mmHg and/ or diastolic BP 85-89 mmHg), grade 1 HTN(systolic BP 140-159 mmHg and/ or diastolic BP 90-99 mmHg), grade 2 HTN (systolic BP 160-179 mmHg and/or diastolic BP 100-109 $\mathrm{mmHg}$ ), and grade $3 \mathrm{HTN}$ (systolic BP $\geq 180 \mathrm{mmHg}$ and/or diastolic BP $\geq 110 \mathrm{mmHg}$ ), with the $\mathrm{BP}$ category to be defined by the highest level of BP, either systolic or diastolic.

Blood indices: Blood samples were drawn in the morning after overnight fasting (duration: eight hours or longer). FPG and fasting insulin was analyzed in accredited laboratories, using similar enzymatic assays in all study centers. HOMA-IR was calculated as indicated by Matthews et al. [29].

\subsection{Statistical Analysis}

Factors associated with HOMA-IR and HTN were identified by Pearson's or Spearman's correlation and analyses of variance. For dietary behavior and physical activity factors, receiver operating characteristic (ROC) analysis was performed and the optimal cut-offs were determined by the point with the shortest distance to $(0,1)$ in the ROC curve that maximizes the sensitivity (Se) and specificity $(\mathrm{Sp})$ of the test. The distance for each observed cut-off was calculated as the square root of $\left[(1-\mathrm{Se})^{2}+(1-\mathrm{Sp})^{2}\right]$ [30]. For other variables, such as waist circumference and BMI the cut-off values set by WHO were used. The population was randomly separated to $2 / 3$ and $1 / 3$ for the development ( $n=1076 \mathrm{IR}$ cohort and $n=906 \mathrm{HTN}$ cohort) and validation ( $n=505 \mathrm{IR}$ cohort and $n=444 \mathrm{HTN}$ cohort) of the indices respectively. For the development of the risk assessment indices, backward linear regressions were performed, with dependent variables the percentiles of HOMA-IR and 5 categories of HTN classification, respectively. The exclusion criteria of independent variables were set at $p>0.10$. The adjusted $\beta$-coefficients were multiplied and rounded to the nearest integer value as needed so as to sum up to 40 points. In order to validate the indices, ROC analysis was performed to the validation cohort. The scores with the best combination of Se and Sp (determined as described previously), for 75th and 95th percentile for HOMA-IR, and for grade 2 and 3 HTN, respectively, were used as cut-off scores for the interpretation of the results. The statistical analyses were performed using the Statistical Package for Social Sciences (SPSS Inc., Chicago, IL, USA), version 21.0.

\section{Results}

The descriptive characteristics of the study population for the European IR Risk Index and the European HTN Risk Index are presented in Table 1. Moreover, the sex distribution was 33.8\% males and $66.2 \%$ females and $31.9 \%$ males and $68.1 \%$ females, for European IR Risk Index and the European HTN Risk Index, respectively. None of the aforementioned variables differed significantly between development and validation cohorts. 
Table 1. Descriptive characteristics of the European IR Risk Index and European HTN Risk Index.

\begin{tabular}{|c|c|c|c|}
\hline & $\begin{array}{c}\text { Development } \\
\text { Cohort } \\
\text { Mean } \pm \text { SD }\end{array}$ & $\begin{array}{c}\text { Validation } \\
\text { Cohort } \\
\text { Mean } \pm \text { SD }\end{array}$ & $p$ Value \\
\hline $\begin{array}{l}\text { European IR Risk Index } \\
\qquad(n=1581)\end{array}$ & $n=1076$ & $n=505$ & \\
\hline Age (years) & $40.7 \pm 5.29$ & $40.6 \pm 5.15$ & 0.666 \\
\hline \multicolumn{4}{|l|}{ BMI $\left(\mathrm{kg} / \mathrm{m}^{2}\right)$} \\
\hline male & $29.7 \pm 3.97$ & $29.2 \pm 4.39$ & 0.172 \\
\hline female & $27.3 \pm 5.69$ & $27.3 \pm 5.67$ & 0.985 \\
\hline \multicolumn{4}{|l|}{ Waist circumference $(\mathrm{cm})$} \\
\hline male & $102.7 \pm 9.93$ & $101.0 \pm 11.64$ & 0.068 \\
\hline female & $88.7 \pm 13.31$ & $89.1 \pm 12.95$ & 0.619 \\
\hline HOMA-IR & $2.0 \pm 2.40$ & $1.9 \pm 1.39$ & 0.340 \\
\hline $\mathrm{SBP}(\mathrm{mmHg})$ & $116.8 \pm 16.20$ & $116.4 \pm 15.47$ & 0.673 \\
\hline $\mathrm{DBP}(\mathrm{mmHg})$ & $77.7 \pm 11.39$ & $77.0 \pm 10.37$ & 0.242 \\
\hline $\begin{array}{l}\text { European HTN Risk } \\
\text { Index }(n=1350)\end{array}$ & $n=906$ & $n=444$ & \\
\hline Age (years) & $40.1 \pm 5.34$ & $40.3 \pm 5.47$ & 0.590 \\
\hline \multicolumn{4}{|l|}{$\operatorname{BMI}\left(\mathrm{kg} / \mathrm{m}^{2}\right)$} \\
\hline male & $29.2 \pm 3.58$ & $29.1 \pm 3.89$ & 0.224 \\
\hline female & $27.1 \pm 5.04$ & $27.2 \pm 5.48$ & 0.930 \\
\hline \multicolumn{4}{|l|}{ Waist circumference $(\mathrm{cm})$} \\
\hline male & $102.8 \pm 10.77$ & $101.7 \pm 12.07$ & 0.330 \\
\hline female & $87.6 \pm 13.17$ & $88.7 \pm 13.41$ & 0.268 \\
\hline HOMA-IR & $2.2 \pm 2.80$ & $2.0 \pm 1.46$ & 0.145 \\
\hline $\mathrm{SBP}(\mathrm{mmHg})$ & $117.5 \pm 17.06$ & $116.7 \pm 16.51$ & 0.466 \\
\hline DBP (mmHg) & $77.9 \pm 12.13$ & $76.8 \pm 11.06$ & 0.092 \\
\hline
\end{tabular}

BMI: Body Mass Index; HOMA-IR: Homeostatic Model Assessment of Insulin Resistance Index; SBP: Systolic blood pressure; DBP: Diastolic blood pressure.

Regarding the European IR Risk index, the parameters found to be significantly associated with the HOMA-IR were: number of breakfast occasions per week, unsweetened and sweetened milk consumption, sugary drinks consumption, fish, red meat, fruits and vegetables consumption, BMI, sex, waist circumference, number of walking sessions during the week lasting at least $30 \mathrm{~min}$, number of vigorous physical activity sessions during the week lasting at least $10 \mathrm{~min}$ and leisure screen time (i.e., television, video games, computers, etc.). At the final model the variables found to be statistically significant in identifying the HOMA-IR percentiles after the stepwise procedure were BMI, screen time, sex, breakfast, sugary drinks, waist circumference, walking and vigorous physical activity as shown in Table 2. 
Table 2. Scores for European IR Risk Index.

\begin{tabular}{|c|c|c|c|c|}
\hline HOMA-IR Model & $\mathbf{b}$ & $p$ Value & Cut-Offs & Points Allocated \\
\hline BMI & $\begin{array}{c}- \\
0.340 \\
0.680\end{array}$ & 0.001 & $\begin{array}{c}<25 \mathrm{~kg} / \mathrm{m}^{2} \\
25-30 \mathrm{~kg} / \mathrm{m}^{2} \\
>30 \mathrm{~kg} / \mathrm{m}^{2}\end{array}$ & $\begin{array}{c}0 \\
9 \\
19\end{array}$ \\
\hline $\begin{array}{l}\text { Waist Circumference (women and } \\
\text { men respectively) }\end{array}$ & $\begin{array}{c}- \\
0.118 \\
0.236\end{array}$ & 0.003 & $\begin{array}{c}<80 \mathrm{~cm} \text { or }<94 \mathrm{~cm} \\
80-88 \mathrm{~cm} \text { or } 94-102 \mathrm{~cm} \\
>88 \mathrm{~cm} \text { or }>102 \mathrm{~cm}\end{array}$ & $\begin{array}{l}0 \\
3 \\
7\end{array}$ \\
\hline Screen time & 0.113 & 0.001 & $\begin{array}{l}<2 \mathrm{~h} / \text { day } \\
\geq 2 \mathrm{~h} / \text { day }\end{array}$ & $\begin{array}{l}0 \\
3\end{array}$ \\
\hline Sex & 0.066 & 0.023 & $\begin{array}{l}\text { female } \\
\text { male }\end{array}$ & $\begin{array}{l}0 \\
2\end{array}$ \\
\hline Breakfast & 0.095 & 0.001 & $\begin{array}{l}\geq 5 \text { times/week } \\
<5 \text { times/week }\end{array}$ & $\begin{array}{l}0 \\
3\end{array}$ \\
\hline Sugary drinks $(1$ portion $=250 \mathrm{~mL})$ & 0.063 & 0.018 & $\begin{array}{l}<1 \text { portion/week } \\
\geq 1 \text { portion/week }\end{array}$ & $\begin{array}{l}0 \\
2\end{array}$ \\
\hline $\begin{array}{c}\text { Walking } \\
\text { (3 days/ week for at least } 30 \mathrm{~min} \text { ) }\end{array}$ & $\overline{-}$ & 0.033 & $\begin{array}{l}\text { Yes } \\
\text { No }\end{array}$ & $\begin{array}{l}0 \\
2\end{array}$ \\
\hline $\begin{array}{c}\text { Vigorous physical activity } \\
\text { (3 days/ week for at least } 10 \mathrm{~min} \text { ) }\end{array}$ & $\begin{array}{c}- \\
0.084\end{array}$ & 0.002 & $\begin{array}{l}\text { Yes } \\
\text { No }\end{array}$ & $\begin{array}{l}0 \\
2\end{array}$ \\
\hline Maximum total points & & & & 40 \\
\hline
\end{tabular}

b: standardizes-coefficient; BMI: Body Mass Index; HOMA-IR: Homeostatic Model Assessment of Insulin Resistance Index.

As for the European HTN Risk Index the parameters found to be significantly associated with the BP categories as determined by the ESH were: number of cigarettes per day, number of lunch occasions per week, morning snacks per week, afternoon snacks per week, evening snacks per week, whole grain foods consumption (i.e., whole wheat bread, breakfast cereals), fruits and vegetables, red meat, white meat, fish, nuts and legumes consumption, alcohol intake, and leisure screen time (i.e., television, video games, computers, etc.). At the final model the variables that were found to be statistically significant in identifying grade 2 and $3 \mathrm{HTN}$ after the stepwise procedure were legumes consumption, alcohol intake, sex, age, BMI, and vigorous physical activity, as shown in Table 3. 
Table 3. Scores for European HTN Risk Index.

\begin{tabular}{|c|c|c|c|c|}
\hline Hypertension Model & $\mathbf{b}$ & $p$ Value & Cut-Offs & Points Allocated \\
\hline BMI & $\begin{array}{c}- \\
0.308 \\
0.616\end{array}$ & 0.001 & $\begin{array}{c}<25 \mathrm{~kg} / \mathrm{m}^{2} \\
25-30 \mathrm{~kg} / \mathrm{m}^{2} \\
>30 \mathrm{~kg} / \mathrm{m}^{2}\end{array}$ & $\begin{array}{c}0 \\
10 \\
20\end{array}$ \\
\hline Sex & 0.204 & 0.001 & $\begin{array}{l}\text { female } \\
\text { male }\end{array}$ & $\begin{array}{l}0 \\
6\end{array}$ \\
\hline $\begin{array}{l}\text { Vigorous physical activity } \\
\text { (3 days/ week for at least } 10 \mathrm{~min} \text { ) }\end{array}$ & 0.048 & 0.091 & $\begin{array}{l}\text { Yes } \\
\text { No }\end{array}$ & $\begin{array}{l}0 \\
2\end{array}$ \\
\hline Legumes & 0.254 & 0.001 & $\begin{array}{l}\geq 1 \mathrm{cup} / \text { week } \\
<1 \mathrm{cup} / \text { week }\end{array}$ & $\begin{array}{l}0 \\
8\end{array}$ \\
\hline $\begin{array}{c}\text { Alcohol } \\
(1 \text { portion }=125 \mathrm{~mL} \text { of wine, } 330 \mathrm{~mL} \\
\text { of beer or } 40 \mathrm{~mL} \text { of hard liquor })\end{array}$ & 0.069 & 0.020 & $\begin{array}{l}<3 \text { portions/week } \\
\geq 3 \text { portions/week }\end{array}$ & $\begin{array}{l}0 \\
2\end{array}$ \\
\hline Age & $\begin{array}{c}- \\
0.047\end{array}$ & 0.099 & $\begin{array}{l}<40 \text { years } \\
\geq 40 \text { years }\end{array}$ & $\begin{array}{l}0 \\
2\end{array}$ \\
\hline Maximum total points & & & & 40 \\
\hline
\end{tabular}

b: standardizes-coefficient; BMI: Body Mass Index; HTN: Hypertension.

The ROC analysis in the validation cohort indicated an area under the curve (AUC) 0.768 (95\%CI: 0.721-0.815) for identifying individuals above the 75th percentile of HOMA-IR. The index cut-off score for identifying individuals above the 75 th percentile was $23 / 40$, as indicated by the optimal match of Se and Sp (0.720 and 0.691, respectively) (Table 4, Figure 1). Furthermore, the indicated AUC for identifying individuals above the 95th percentile of HOMA-IR was 0.828 (95\%CI: 0.766-0.890). The index cut-off score for identifying individuals above the 95th percentile was 31/40, as indicated by the optimal match of Se and Sp (0.696 and 0.778, respectively) (Table 4, Figure 2). Regarding HTN, the ROC analysis in the validation cohort indicated an AUC 0.778 (95\%CI: 0.680-0.876) for identifying individuals with grade 2 and 3 hypertension. The index cut-off score for identifying individuals with grade 2 and 3 hypertension was 26/40, as indicated by the optimal match of Se and Sp (0.667 and 0.797, respectively) (Table 4 , Figure 3).

Table 4. ROC characteristics of European IR Risk Index and European HTN Risk Index in the validation cohort.

\begin{tabular}{|c|c|c|c|c|c|c|c|c|c|}
\hline & Score & AUC & $\begin{array}{l}95 \% \\
\text { Confidence } \\
\text { Interval }\end{array}$ & $n$ of TP & $n$ of Un & PPV \% & NPV \% & Se & $\mathrm{Sp}$ \\
\hline $\begin{array}{l}\text { European IR Risk Index }(n=505) \\
\text { Cut off score for Identifying individuals } \\
\text { above } 75 \text { th percentile of HOMA-IR }\end{array}$ & $23 / 40$ & 0.768 & $0.721-0.815$ & 95 & 37 & $45.5 \%$ & $87.5 \%$ & 0.720 & 0.691 \\
\hline $\begin{array}{l}\text { Cut off score for Identifying individuals } \\
\text { above 95th percentile of HOMA-IR }\end{array}$ & $31 / 40$ & 0.828 & $0.766-0.890$ & 16 & 7 & $13.0 \%$ & $98.2 \%$ & 0.696 & 0.778 \\
\hline $\begin{array}{l}\text { European HTN Risk Index }(n=444) \\
\text { Cut off for detecting 2nd and 3rd } \\
\text { grade hypertension }\end{array}$ & $26 / 40$ & 0.778 & $0.680-0.876$ & 14 & 7 & $14.0 \%$ & $97.8 \%$ & 0.667 & 0.797 \\
\hline
\end{tabular}




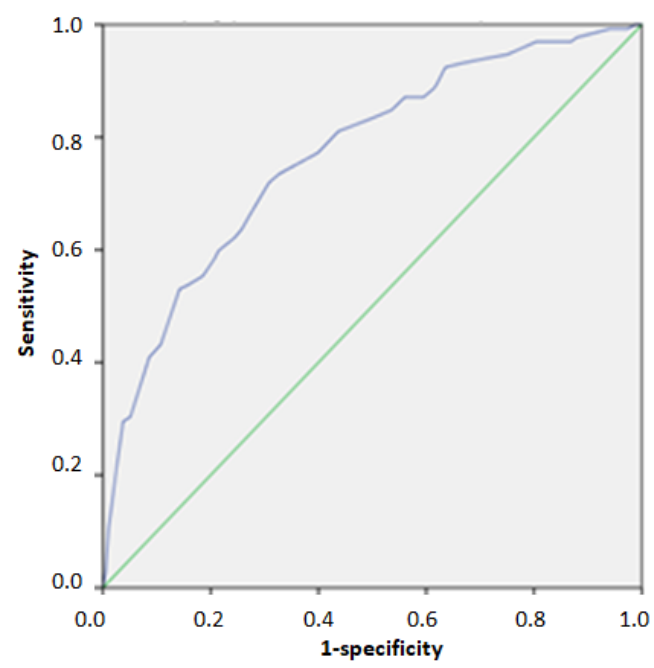

Figure 1. ROC Curve for identifying individuals above the 75th percentile of HOMA-IR.

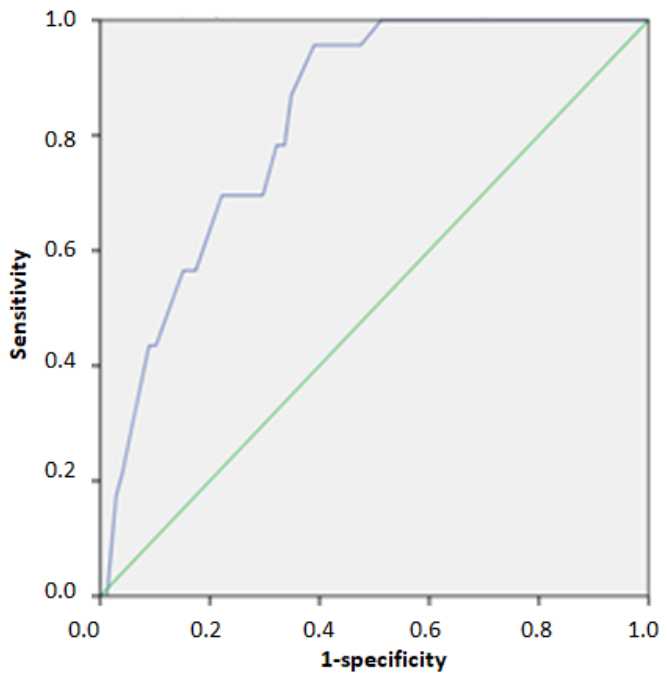

Figure 2. ROC Curve for identifying individuals above the 95th percentile of HOMA-IR.

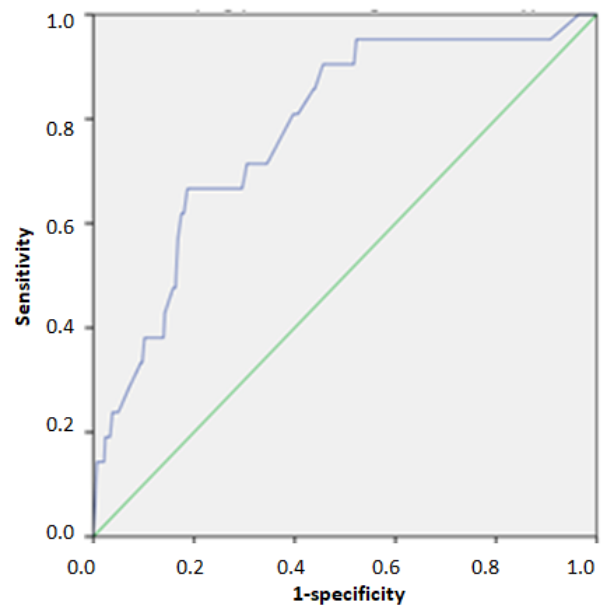

Figure 3. ROC Curve for identifying individuals with grade 2 and 3 hypertension.

\section{Discussion}

The ongoing increase in the prevalence of T2DM and HTN and their acknowledged impact on public health highlight the strain for more appropriate strategies and tools for their early diagnosis and 
prevention. Since both of these metabolic abnormalities may be provoked by the interaction of various risk factors relevant to family history, anthropometric indices and lifestyle parameters, such as dietary behaviors and physical activity, their assessment is necessary so as to design effective prevention strategies. Therefore, the development and implementation of screening tools evaluating holistically various health-related variables can be of a great importance in order to easily identify people at risk, so as to be referred for further evaluation at primary healthcare settings. The aim of the current study was to develop two risk assessment indices for the identification of IR and grade 2 and 3 HTN.

A number of risk scores to predict T2DM risk already exist in the literature $[14,15,19,31]$, but most of them do not apply at various cases such as different races or socioeconomic status. One of the most reliable and valid tools for the identification of people at increased risk for T2DM is the FINDRISC [13], which was initially developed on the Finnish population, showing high Se and $\mathrm{Sp}$ values. Thereafter, it has been validated in other European ethnicities with good validity results [32-35]. Despite the fact that the FINDRISC has been designed on a specific population, it seems that the use of different cut-offs in different national groups may manage equivalent accuracy [36-38]. Similarly, an accurate easy-to-use online tool for the detection of impaired glucose regulation and T2DM is the Leicester Risk Assessment Score, an index developed in a multiethnic UK population with a high probability to identify population at risk [18]. Likewise, the Australian index AUSDRISK (The Australian Type 2 Diabetes Risk Assessment Tool) is considered of satisfactory Se and Sp but no studies have examined its validity in different ethnicities [14]. In general, the majority of tools available in the literature have been found to have satisfactory predictive values, but these values may be limited in the country developed [31] or some score components that are prerequisite for the completion of some tools such as blood indices measurements or the awareness of unfavorable glycaemia indices $[13,15,19]$ makes them non-applicable when individuals have not previously undergone any blood testing.

The aforementioned tools are used for the assessment of the T2DM risk, the early identification of which is a major public health issue. Indeed, the early identification and management of IR may significantly decrease the risk for T2DM and cardiovascular disease (CVD) [39]. Furthermore, individuals in the highest HOMA-IR quintiles for IR have even greater risk for CVD [40]. The main benefit of pre-diabetes early identification is that it does not require medical management. The modification of lifestyle parameters, such as increase physical activity or decrease time devoted to sedentary activities, weight loss, adopting healthy dietary habits, etc., may be important measures in order to prevent the onset of glycaemic abnormalities [41-44], and thus to lower its economic public health burden [45].

Likewise, the existing risk scores for predicting HTN are either developed in population-specific groups or use as variables the measurements of systolic and diastolic BP [16], which has a large impact on the feasibility and thus the reach of these screening tools. For instance, the population cohort in the risk score of Kshirsagar et al. was middle-aged and older adults [17], and despite a satisfactory AUC (0.75-0.78), it is difficult to apply it in different age groups. Similarly, the risk index of the Strong Heart Study was developed in an American Indian population [23]. Despite the fact that obesity and hyperinsulinaemia affect less the BP of American Indians [46], it seems that the development of HTN in this ethnic group has a more severe effect on cardiovascular health [47]. One of the possible reasons for these findings in the American Indians is the presence of three genes with multiple single nucleotide polymorphisms associated with systolic BP [48]. Therefore, the development of more population-representative and self-reported risk scores is needed to identify HTN accurately.

In the current study, we developed two self-reported risk assessment indices, the European IR Risk Index and European HTN Risk Index for the identification of IR at 75th and 95th percentile according to HOMA-IR score and grade 2 and 3HTN. Both risk scores are calculated from a total of eleven components, and no biochemical, BP or other measurements are required. This makes these indices very easy-to-calculate, and applicable for a wide range of populations regardless their access to medical equipment, healthcare services, or their willingness to go through a medical check-up. Furthermore, by including anthropometric, dietary and physical activity components in the indices, 
the importance of lifestyle modification is highlighted. Specifically, the importance of increasing physical activity, along with breakfast and legume consumption, and of decreasing sugary drinks and alcohol consumption is highlighted. In addition, based on the ROC analyses, both the European IR Risk Index and the European HTN Risk Index were found to perform well in identifying individuals above 75th and 95th percentile of HOMA-IR and at grade 2 and 3 HTN (Table 4). The AUCs of 0.768, $0.828,0.778$, respectively, are slightly higher than the relevant of risk assessment indices available in the literature, which range from 0.72 to $0.78[13,14,17,18,31,49]$, despite not incorporating biochemical and BP measurements. Another great advantage of the current indices is that the study population in which they have been developed and validated is from six countries in Europe, making them applicable and preferable for a wide range of Caucasian populations. The potential limitations of our study could be the fact that although it is based on a community cohort, the cohorts recruited from each country are not representative of the general population, as the recruitment took place only in one large region within each country, and with probably different risk of developing T2DM than the overall population according to FINDRISC. Overall, the findings are encouraging for the next steps in validating these risk assessment indices in more specific European populations.

\section{Conclusions}

T2DM and HTN are, without any doubt, the major risk factors for CVD. Moreover, there is robust evidence that they can be prevented and treated through lifestyle interventions. The disparity among populations around Europe has highlighted the need for simple novel screening tools, without the use of biochemical or other clinical indices in order to identify individuals at increased risk, so as to motivate them to seek medical assistance and proceed with lifestyle modification. The developed European IR Risk Index and European HTN Risk Index in the present study are easy-to-apply, valid, non-invasive, and low-cost for identifying European adults at high risk for developing T2DM or having HTN.

Author Contributions: Conceptualization, S.K., C.M., K.K. and Y.M.; methodology, S.K. and Y.M.; formal analysis, S.K. and Y.M.; investigation and data collection, S.K., C.M., K.K., J.L., G.C., V.I., K.W., S.S., L.A.M., K.T., E.B., R.D., E.A., S.L., K.M. and Y.M.; resources, Y.M., J.L., G.C., V.I., L.A.M. and K.M.; data curation, S.K., C.M. and Y.M.; writing—original draft preparation, S.K., C.M., K.K. and Y.M.; writing-review and editing, S.K., C.M., K.K., J.L., G.C., V.I., K.W., S.S., L.A.M., K.T., E.B., R.D., E.A., S.L., K.M. and Y.M.; visualization, S.K., C.M., K.K.; supervision, Y.M.; project administration, Y.M.; funding acquisition, Y.M., J.L., G.C., V.I., L.A.M. and K.M.; All authors have read and agreed to the published version of the manuscript.

Funding: The Feel4Diabetes-study has received funding from the European Union's Horizon 2020 research and innovation programme [Grant Agreement: $\mathrm{n}$ 643708]. The content of this article reflects only the authors' views and the European Community is not liable for any use that may be made of the information contained therein. For the current research work C.M was supported by the Hellenic Foundation for Research and Innovation (HFRI) and the General Secretariat for Research and Technology (GSRT), under the HFRI PhD Fellowship grant (GA. no. 466; 133218/I2; 04/08/2017).

Acknowledgments: The authors would like to thank the members of the Feel4Diabetes-study group: Coordinator: Yannis Manios, Steering Committee: Yannis Manios, Greet Cardon, Jaana Lindström, Peter Schwarz, Konstantinos Makrilakis, Lieven Annemans, Winne Ko, Harokopio University (Greece): Yannis Manios, Kalliopi Karatzi, Odysseas Androutsos, George Moschonis, Spyridon Kanellakis, Christina Mavrogianni, Konstantina Tsoutsoulopoulou, Christina Katsarou, Eva Karaglani, Irini Qira, Efstathios Skoufas, Konstantina Maragkopoulou, Antigone Tsiafitsa, Irini Sotiropoulou, Michalis Tsolakos, Effie Argyri, Mary Nikolaou, Eleni-Anna Vampouli, Christina Filippou, Kyriaki Apergi, Amalia Filippou, Gatsiou Katerina, Efstratios Dimitriadis, Finnish Institute for Health and Welfare (Finland): Jaana Lindström, Tiina Laatikainen, Katja Wikström, Jemina Kivelä, Päivi Valve, Esko Levälahti, Eeva Virtanen, Tiina Pennanen, Seija Olli, Karoliina Nelimarkka, Ghent University (Belgium), Department of Movement and Sports Sciences: Greet Cardon, Vicky Van Stappen, Nele Huys, Department of Public Health: Lieven Annemans, Ruben Willems, Department of Endocrinology and Metabolic Diseases: Samyah Shadid, Technische Universität Dresden (Germany): Peter Schwarz, Patrick Timpel, University of Athens (Greece), Konstantinos Makrilakis, Stavros Liatis, George Dafoulas, Christina-Paulina Lambrinou, Angeliki Giannopoulou, International Diabetes Federation European Region (Belgium): Winne Ko, Ernest Karuranga, Universidad De Zaragoza (Spain): Luis Moreno, Fernando Civeira, Gloria Bueno, Pilar De Miguel-Etayo, Esther Ma Gonzalez-Gil, María L. Miguel-Berges, Natalia Giménez-Legarre; Paloma Flores-Barrantes, Aleli M. Ayala-Marín, Miguel Seral-Cortés, Lucia Baila-Rueda, Ana Cenarro, Estíbaliz Jarauta, Rocío Mateo-Gallego, Medical University of Varna (Bulgaria): Violeta Iotova, 
Tsvetalina Tankova, Natalia Usheva, Kaloyan Tsochev, Nevena Chakarova, Sonya Galcheva, Rumyana Dimova, Yana Bocheva, Zhaneta Radkova, Vanya Marinova, Yuliya Bazdarska, Tanya Stefanova, University of Debrecen (Hungary): Imre Rurik, Timea Ungvari, Zoltán Jancsó, Anna Nánási, László Kolozsvári, Csilla Semánova, Éva Bíró, Emese Antal, Sándorné Radó: Extensive Life Oy (Finland): Remberto Martinez, Marcos Tong.

Conflicts of Interest: The authors declare no conflict of interest.

\section{References}

1. Saeedi, P.; Petersohn, I.; Salpea, P.; Malanda, B.; Karuranga, S.; Unwin, N.; Colagiuri, S.; Guariguata, L.; Motala, A.A.; Ogurtsova, K.; et al. Global and regional diabetes prevalence estimates for 2019 and projections for 2030 and 2045: Results from the International Diabetes Federation Diabetes Atlas, 9th ed. Diabetes Res. Clin. Pract. 2019, 157, 107843. [CrossRef] [PubMed]

2. GBD 2013 Risk Factors Collaborators; Forouzanfar, M.H.; Alexander, L.; Anderson, H.R.; Bachman, V.F.; Biryukov, S.; Brauer, M.; Burnett, R.; Casey, D.; Coates, M.M.; et al. Global, regional, and national comparative risk assessment of 79 behavioural, environmental and occupational, and metabolic risks or clusters of risks in 188 countries, 1990-2013: A systematic analysis for the Global Burden of Disease Study 2013. Lancet 2015, 386, 2287-2323. [CrossRef]

3. Forouzanfar, M.H.; Liu, P.; Roth, G.A.; Ng, M.; Biryukov, S.; Marczak, L.; Alexander, L.; Estep, K.; Hassen Abate, K.; Akinyemiju, T.F.; et al. Global Burden of Hypertension and Systolic Blood Pressure of at Least 110 to $115 \mathrm{~mm} \mathrm{Hg}$, 1990-2015. JAMA 2017, 317, 165-182. [CrossRef]

4. Siu, A.L. Force USPST: Screening for high blood pressure in adults: U.S. Preventive Services Task Force recommendation statement. Ann. Intern. Med. 2015, 163, 778-786. [CrossRef]

5. Ekoe, J.M.; Goldenberg, R.; Katz, P. Screening for Diabetes in Adults. Can. J. Diabetes 2018, 42 (Suppl. S1), S16-S19. [CrossRef]

6. Fleming, S.; Atherton, H.; McCartney, D.; Hodgkinson, J.; Greenfield, S.; Hobbs, F.D.; Mant, J.; McManus, R.J.; Thompson, M.; Ward, A.; et al. Self-Screening and Non-Physician Screening for Hypertension in Communities: A Systematic Review. Am. J. Hypertens. 2015, 28, 1316-1324. [CrossRef]

7. Gilmer, T.P.; O'Connor, P.J. The growing importance of diabetes screening. Diabetes Care 2010, 33, $1695-1697$. [CrossRef]

8. American Diabetes Association. Classification and Diagnosis of Diabetes: Standards of Medical Care in Diabetes-2018. Diabetes Care 2018, 41 (Suppl. S1), S13-S27. [CrossRef]

9. Taylor, J. 2013 ESH/ESC guidelines for the management of arterial hypertension. Eur. Heart J. 2013, 34, 2108-2109.

10. NCD Risk Factor Collaboration (NCD-RisC). Long-term and recent trends in hypertension awareness, treatment, and control in 12 high-income countries: An analysis of 123 nationally representative surveys. Lancet 2019, 394, 639-651. [CrossRef]

11. Gong, W.; Lu, B.; Yang, Z.; Ye, W.; Du, Y.; Wang, M.; Li, Q.; Zhang, W.; Pan, Y.; Feng, X.; et al. Early-stage atherosclerosis in newly diagnosed, untreated type 2 diabetes mellitus and impaired glucose tolerance. Diabetes Metab. 2009, 35, 458-462. [CrossRef] [PubMed]

12. Chaturvedi, N. The burden of diabetes and its complications: Trends and implications for intervention. Diabetes Res. Clin. Pract. 2007, 76 (Suppl. S1), S3-S12. [CrossRef] [PubMed]

13. Lindstrom, J.; Tuomilehto, J. The diabetes risk score: A practical tool to predict type 2 diabetes risk. Diabetes Care 2003, 26, 725-731. [CrossRef]

14. Chen, L.; Magliano, D.J.; Balkau, B.; Colagiuri, S.; Zimmet, P.Z.; Tonkin, A.M.; Mitchell, P.; Phillips, P.J.; Shaw, J.E. AUSDRISK: An Australian Type 2 Diabetes Risk Assessment Tool based on demographic, lifestyle and simple anthropometric measures. Med. J. Aust. 2010, 192, 197-202. [CrossRef]

15. Hippisley-Cox, J.; Coupland, C. Development and validation of QDiabetes-2018 risk prediction algorithm to estimate future risk of type 2 diabetes: Cohort study. BMJ 2017, 359, 5019. [CrossRef]

16. Parikh, N.I.; Pencina, M.J.; Wang, T.J.; Benjamin, E.J.; Lanier, K.J.; Levy, D.; D’'Agostino, R.B.; Kannel, W.B., Sr.; Vasan, R.S. A risk score for predicting near-term incidence of hypertension: The Framingham Heart Study. Ann. Intern. Med. 2008, 148, 102-110. [CrossRef]

17. Kshirsagar, A.V.; Chiu, Y.L.; Bomback, A.S.; August, P.A.; Viera, A.J.; Colindres, R.E.; Bang, H. A hypertension risk score for middle-aged and older adults. J. Clin. Hypertens. 2010, 12, 800-808. [CrossRef] 
18. Gray, L.J.; Taub, N.A.; Khunti, K.; Gardiner, E.; Hiles, S.; Webb, D.R.; Srinivasan, B.T.; Davies, M.J. The Leicester Risk Assessment score for detecting undiagnosed Type 2 diabetes and impaired glucose regulation for use in a multiethnic UK setting. Diabetic Med. J. Br. Diabetic Assoc. 2010, 27, 887-895. [CrossRef]

19. Schmidt, M.I.; Duncan, B.B.; Bang, H.; Pankow, J.S.; Ballantyne, C.M.; Golden, S.H.; Folsom, A.R.; Chambless, L.E. Atherosclerosis Risk in Communities I: Identifying individuals at high risk for diabetes: The Atherosclerosis Risk in Communities study. Diabetes Care 2005, 28, 2013-2018. [CrossRef]

20. Xiang, A.H.; Wang, C.; Peters, R.K.; Trigo, E.; Kjos, S.L.; Buchanan, T.A. Coordinate changes in plasma glucose and pancreatic beta-cell function in Latino women at high risk for type 2 diabetes. Diabetes 2006, 55, 1074-1079. [CrossRef] [PubMed]

21. Rutter, M.K.; Meigs, J.B.; Sullivan, L.M.; D'Agostino, R.B., Sr.; Wilson, P.W. Insulin resistance, the metabolic syndrome, and incident cardiovascular events in the Framingham Offspring Study. Diabetes 2005, 54, 3252-3257. [CrossRef] [PubMed]

22. Czech, M.P. Insulin action and resistance in obesity and type 2 diabetes. Nat. Med. 2017, $23,804-814$. [CrossRef] [PubMed]

23. Wang, W.; Lee, E.T.; Fabsitz, R.R.; Devereux, R.; Best, L.; Welty, T.K.; Howard, B.V. A longitudinal study of hypertension risk factors and their relation to cardiovascular disease: The Strong Heart Study. Hypertension 2006, 47, 403-409. [CrossRef] [PubMed]

24. Muntner, P.; Shimbo, D.; Carey, R.M.; Charleston, J.B.; Gaillard, T.; Misra, S.; Myers, M.G.; Ogedegbe, G.; Schwartz, J.E.; Townsend, R.R.; et al. Measurement of Blood Pressure in Humans: A Scientific Statement From the American Heart Association. Hypertension 2019, 73, e35-e66. [CrossRef]

25. World Medical Association Declaration of Helsinki. Ethical principles for medical research involving human subjects. JAMA 2013, 310, 2191-2194. [CrossRef]

26. Manios, Y.; Androutsos, O.; Lambrinou, C.P.; Cardon, G.; Lindstrom, J.; Annemans, L.; Mateo-Gallego, R.; de Sabata, M.S.; Iotova, V.; Kivela, J.; et al. A school- and community-based intervention to promote healthy lifestyle and prevent type 2 diabetes in vulnerable families across Europe: Design and implementation of the Feel4Diabetes-study. Public Health Nutr. 2018, 21, 3281-3290. [CrossRef]

27. World Health Organization. Obesity: Preventing and managing the global epidemic. Report of a WHO consultation. World Health Organ. Tech. Rep. Ser. 2000, 894, 1-253.

28. Williams, B.; Mancia, G.; Spiering, W.; Rosei, E.A.; Azizi, M.; Burnier, M.; Clement, D.L.; Coca, A.; de Simone, G.; Dominiczak, A.; et al. ESC Scientific Document Group: [2018 ESC/ESH Guidelines for the management of arterial hypertension. The Task Force for the management of arterial hypertension of the European Society of Cardiology (ESC) and the European Society of Hypertension (ESH)]. G. Ital. Cardiol. 2018, 19 (Suppl. S1), 3S-73S.

29. Matthews, D.R.; Hosker, J.P.; Rudenski, A.S.; Naylor, B.A.; Treacher, D.F.; Turner, R.C. Homeostasis model assessment: Insulin resistance and beta-cell function from fasting plasma glucose and insulin concentrations in man. Diabetologia 1985, 28, 412-419. [CrossRef]

30. Perkins, N.J.; Schisterman, E.F. The inconsistency of optimal cutpoints obtained using two criteria based on the receiver operating characteristic curve. Am. J. Epidemiol. 2006, 163, 670-675. [CrossRef]

31. Robinson, C.A.; Agarwal, G.; Nerenberg, K. Validating the CANRISK prognostic model for assessing diabetes risk in Canada's multi-ethnic population. Chronic Dis. Inj. Can. 2011, 32, 19-31. [PubMed]

32. Costa, B.; Barrio, F.; Pinol, J.L.; Cabre, J.J.; Mundet, X.; Sagarra, R.; Salas-Salvado, J.; Sola-Morales, O.; DE-PLAN-CAT/PREDICE Research Group. Shifting from glucose diagnosis to the new HbA1c diagnosis reduces the capability of the Finnish Diabetes Risk Score (FINDRISC) to screen for glucose abnormalities within a real-life primary healthcare preventive strategy. BMC Med. 2013, 11, 45. [CrossRef] [PubMed]

33. Franciosi, M.; De Berardis, G.; Rossi, M.C.; Sacco, M.; Belfiglio, M.; Pellegrini, F.; Tognoni, G.; Valentini, M.; Nicolucci, A. Use of the diabetes risk score for opportunistic screening of undiagnosed diabetes and impaired glucose tolerance: The IGLOO (Impaired Glucose Tolerance and Long-Term Outcomes Observational) study. Diabetes Care 2005, 28, 1187-1194. [CrossRef] [PubMed]

34. Makrilakis, K.; Liatis, S.; Grammatikou, S.; Perrea, D.; Stathi, C.; Tsiligros, P.; Katsilambros, N. Validation of the Finnish diabetes risk score (FINDRISC) questionnaire for screening for undiagnosed type 2 diabetes, dysglycaemia and the metabolic syndrome in Greece. Diabetes Metab. 2011, 37, 144-151. [CrossRef] 
35. Tankova, T.; Chakarova, N.; Atanassova, I.; Dakovska, L. Evaluation of the Finnish Diabetes Risk Score as a screening tool for impaired fasting glucose, impaired glucose tolerance and undetected diabetes. Diabetes Res. Clin. Pract. 2011, 92, 46-52. [CrossRef]

36. Mavrogianni, C.; Lambrinou, C.P.; Androutsos, O.; Lindstrom, J.; Kivela, J.; Cardon, G.; Huys, N.; Tsochev, K.; Iotova, V.; Chakarova, N.; et al. Evaluation of the Finnish Diabetes Risk Score as a screening tool for undiagnosed type 2 diabetes and dysglycaemia among early middle-aged adults in a large-scale European cohort. The Feel4Diabetes-study. Diabetes Res. Clin. Pract. 2019, 150, 99-110. [CrossRef]

37. Gomez-Arbelaez, D.; Alvarado-Jurado, L.; Ayala-Castillo, M.; Forero-Naranjo, L.; Camacho, P.A.; Lopez-Jaramillo, P. Evaluation of the Finnish Diabetes Risk Score to predict type 2 diabetes mellitus in a Colombian population: A longitudinal observational study. World J. Diabetes 2015, 6, 1337-1344. [CrossRef]

38. Zhang, L.; Zhang, Z.; Zhang, Y.; Hu, G.; Chen, L. Evaluation of Finnish Diabetes Risk Score in screening undiagnosed diabetes and prediabetes among U.S. adults by gender and race: NHANES 1999-2010. PLoS ONE 2014, 9, e97865. [CrossRef]

39. Fonseca, V.A. Early identification and treatment of insulin resistance: Impact on subsequent prediabetes and type 2 diabetes. Clin. Cornerstone 2007, 8 (Suppl. S7), S7-S18. [CrossRef]

40. Hanley, A.J.; Williams, K.; Stern, M.P.; Haffner, S.M. Homeostasis model assessment of insulin resistance in relation to the incidence of cardiovascular disease: The San Antonio Heart Study. Diabetes Care 2002, 25, 1177-1184. [CrossRef]

41. Schafer, S.; Kantartzis, K.; Machann, J.; Venter, C.; Niess, A.; Schick, F.; Machicao, F.; Haring, H.U.; Fritsche, A.; Stefan, N. Lifestyle intervention in individuals with normal versus impaired glucose tolerance. Eur. J. Clin. Investig. 2007, 37, 535-543. [CrossRef] [PubMed]

42. Ramachandran, A.; Snehalatha, C.; Mary, S.; Mukesh, B.; Bhaskar, A.D.; Vijay, V. Indian Diabetes Prevention P: The Indian Diabetes Prevention Programme shows that lifestyle modification and metformin prevent type 2 diabetes in Asian Indian subjects with impaired glucose tolerance (IDPP-1). Diabetologia 2006, 49, $289-297$. [CrossRef] [PubMed]

43. Galaviz, K.I.; Narayan, K.M.V.; Lobelo, F.; Weber, M.B. Lifestyle and the Prevention of Type 2 Diabetes: A Status Report. Am. J. Lifestyle Med. 2018, 12, 4-20. [CrossRef]

44. Liu, A.Y.; Silvestre, M.P.; Poppitt, S.D. Prevention of type 2 diabetes through lifestyle modification: Is there a role for higher-protein diets? Adv. Nutr. 2015, 6, 665-673. [CrossRef]

45. Herman, W.H.; Hoerger, T.J.; Brandle, M.; Hicks, K.; Sorensen, S.; Zhang, P.; Hamman, R.F.; Ackermann, R.T.; Engelgau, M.M.; Ratner, R.E. Diabetes Prevention Program Research Group. The cost-effectiveness of lifestyle modification or metformin in preventing type 2 diabetes in adults with impaired glucose tolerance. Ann. Intern. Med. 2005, 142, 323-332. [CrossRef]

46. Howard, B.V.; Lee, E.T.; Yeh, J.L.; Go, O.; Fabsitz, R.R.; Devereux, R.B.; Welty, T.K. Hypertension in adult American Indians. The Strong Heart Study. Hypertension 1996, 28, 256-264. [CrossRef]

47. Jolly, S.E.; Koller, K.R.; Metzger, J.S.; Day, G.M.; Silverman, A.; Hopkins, S.E.; Austin, M.A.; Boden-Albala, B.; Ebbesson, S.O.; Boyer, B.B.; et al. Prevalence of Hypertension and Associated Risk Factors in Western Alaska Native People: The Western Alaska Tribal Collaborative for Health (WATCH) Study. J. Clin. Hypertens. 2015, 17, 812-818. [CrossRef]

48. Franceschini, N.; Tao, R.; Liu, L.; Rutherford, S.; Haack, K.; Almasy, L.; Goring, H.H.; Laston, S.; Lee, E.T.; Best, L.G.; et al. Mapping of a blood pressure QTL on chromosome 17 in American Indians of the strong heart family study. BMC Cardiovasc. Disord. 2014, 14, 158. [CrossRef]

49. Schmidt, M.I.; Duncan, B.B.; Vigo, A.; Pankow, J.; Ballantyne, C.M.; Couper, D.; Brancati, F.; Folsom, A.R. Detection of undiagnosed diabetes and other hyperglycemia states: The Atherosclerosis Risk in Communities Study. Diabetes Care 2003, 26, 1338-1343. [CrossRef]

(C) 2020 by the authors. Licensee MDPI, Basel, Switzerland. This article is an open access article distributed under the terms and conditions of the Creative Commons Attribution (CC BY) license (http://creativecommons.org/licenses/by/4.0/). 